\title{
International scientific meetings: relation between structure and function
}

\author{
DAVID EVERED, RUTH PORTER, JONATHAN NUGENT
}

\begin{abstract}
Increasing pressure is being placed on the scientific community to evaluate research activities. Scientific meetings consume a small but important fraction of the research budget. Audit of a well established series of scientific meetings showed that they met their immediate objectives in that they were international and multidisciplinary and provided a forum in which all participants actively contributed to discussion. The meetings had a positive outcome for the participants, leading in many cases to the subsequent exchange of research material $(60 \%$ of participants) and to the establishment of collaborative research projects (31\%). The impact of the meetings on the scientific community at large was assessed by citation analysis, which showed that the proceedings were cited early, often, and over a substantial period.
\end{abstract}

\section{Introduction}

International meetings are a well established part of the infrastructure of science. They originate in the tours that wealthy European scholars undertook in bygone centuries. These scholarly wanderings established a tradition of regular exchange of ideas and information among those interested in the natural sciences. Personal contacts were subsequently developed and reinforced by exchange of letters, by the publication of periodicals, and the founding of learned societies. Scientists in all disciplines have recognised their interdependence and learnt that intellectual interchange is an essential element in the development of conceptual thought. The habit of travel and the establishment of personal contacts has not only persisted but has expanded enormously in recent years. The growth of the scientific community and increasing ease of travel have made it possible for more scientists to meet more often, allowing them to identify common objectives, create mutual trust and good will, and, in many instances, establish collaborative research projects.

Scientific meetings have, however, been the subject of considerable criticism. ${ }^{12}$ Large meetings have been criticised for being impersonal, expensive, and variable in quality, while small meetings have been criticised because, although they may be productive for those who participate, they are inherently elitist and do not meet the needs of younger scientists. These criticisms can be answered in

Ciba Foundation, London W1N 4BN

DAVID EVERED, FRCP, FIBIOL, director

RUTH PORTER, FRCP, FRCPSYCH, former deputy director

JONATHAN NUGENT, PHD, senior scientific officer

Correspondence to: Dr Evered. general terms. Younger scientists need opportunities to present $\vec{\omega}$ work in public and establish contacts with others, and this is generally possible only at larger meetings. The smaller meetings 3 also have their value, permitting more detailed and intensive discussion and, if appropriately organised, providing opportunities.for interdisciplinary contact, which is often difficult or impossible in larger meetings.

The arguments in support of scientific meetings can be stated generally, but objective assessment of their value poses many problems. Nevertheless, there is increasing pressure on the scien-o tific community to evaluate research activities, ${ }^{3-6}$ and there is some ${ }^{\supset}$ merit in considering ways in which the audit process might be $\vec{N}$ applied to participation in scientific meetings, which consumes a $\bigcirc$ small but appreciable fraction of the research budget. This study evaluated a well established series of smaller meetings-the Ciba $\mathbb{D}$ Foundation symposiums. The foundation's principal objective is to promote international cooperation in scientific research. The $\infty$ symposium series was established in 1950 , and 240 symposiums. were held between that date and early in 1984 . The symposiums are designed to be high level meetings that are international and multidisciplinary and encourage active participation by all those $\bar{\partial}$ present. This study examined the extent to which these criteria were met, using the foundation's own detailed records, and also assessed $\mathscr{\complement}$ the impact of the symposiums on the participants and the scientific $\vec{\overrightarrow{ }}$ community as a whole.

\section{Material and methods}

The foundation's records were used to examine the operation of the symposiums and to assess how far they met the stated objectives. Theo following were analysed: numbers of participants; level of active participation; relation between size of meeting and level of active participation; relation between structure of meeting and level of active participation; countries of origin of participants; pattern and frequency of contributions to discussion; and influence of language on the level of active participation.

The impact of the symposiums on participants was assessed by admini-N stering a postal questionnaire to all participants in 40 recent consecutive $>$ symposiums. The survey population consisted of 932 scientists. Altogether 746 questionnaires $(80 \%)$ were completed and returned. The questionnaire, in addition to seeking the participant's opinion of the symposium, also sought to establish how many valuable new contacts the participants $\mathrm{N}^{-}$ established, the proportion of participants who subsequently exchangedo scientific material with other participants, and how many collaborative research projects resulted from contacts made at the symposium.

The impact of the symposiums on the scientific research community as a@ whole was assessed by citation analysis of all symposium publications covering the period 1971-82 inclusive using the Science Citation Index.

\section{ANALYTICAL METHODS}

The analyses relating to the numbers of participants, level of active participation, and relation between size of meeting and level of active participation were carried out on all symposiums except for 19 earlys meetings for which records were incomplete or unpublished or whick을 formed part of a larger meeting. A detailed analysis of format and operation $:$ 
was carried out on the 100 most recent symposiums and a subset of the 20 most recent of this group. These groups were selected to reflect current practice. No change in format or processing of the symposiums took place during this period. Standard statistical techniques were applied, and the methods used are indicated below.

\section{Results}

\section{STRUCTURE AND OPERATION OF SYMPOSIUMS}

Altogether 240 symposiums were held and 6280 scientists participated (mean of 26.2 for each symposium), of whom $3626(58 \%)$ presented papers and $6035(96 \%)$ contributed actively-that is, made at least one contribution to the discussion. The number of participants in individual symposiums ranged from 20 to 97 . There was a significant inverse relation $\left(\chi^{2}=11 \cdot 8\right.$, $\mathrm{p}<0.001$ ) between the numbers of participants and the proportion actively contributing to discussion (table I). More detailed analysis showed that the

TABLE I-Relation between size of meeting and level of participation in 240 symposiums during 1971-82

\begin{tabular}{ccccc}
\hline $\begin{array}{c}\text { Size of } \\
\text { meeting } \\
\text { (No of } \\
\text { participants) }\end{array}$ & $\begin{array}{c}\text { No of } \\
\text { meetings }^{\star}\end{array}$ & $\begin{array}{c}\text { Mean No of } \\
\text { participants }\end{array}$ & $\begin{array}{c}\text { Mean No(\%) } \\
\text { who presented } \\
\text { papers }\end{array}$ & $\begin{array}{c}\text { Mean No (\%) } \\
\text { active in } \\
\text { discussion }\end{array}$ \\
\hline$<25$ & 97 & $23 \cdot 52$ & $14 \cdot 38(61 \cdot 1)$ & $23 \cdot 30(99 \cdot 1)$ \\
$26-30$ & 91 & $27 \cdot 35$ & $16 \cdot 12(58 \cdot 9)$ & $26 \cdot 82(98 \cdot 1)$ \\
$31-35$ & 21 & $32 \cdot 90$ & $17 \cdot 33(52 \cdot 7)$ & $30 \cdot 10(91 \cdot 5)$ \\
$\geqslant 36$ & 12 & $48 \cdot 75$ & $23 \cdot 0(47 \cdot 2)$ & $39 \cdot 08(80 \cdot 2)$ \\
\hline
\end{tabular}

Data from 19 meetings not included because records were inadequate or not published or they formed part of a larger meeting.

level of active participation in the smaller symposiums-that is, those with fewer than 30 participants-rose from $93 \%$ in the early days of the foundation's operation to $99 \%$ in the most recent 100 symposiums. This difference was significant $\left(\chi^{2}=26.6, p<0.001\right)$ and means that only 14 of the last 2500 participants made no active contribution to the meeting. The mean duration of the symposiums increased over the same period from 12 hours 58 minutes to 15 hours 4 minutes, and this change was entirely accounted for by the increased time allocated for discussion. The duration of the discussion periods increased by $38 \%$ from 6 hours 8 minutes to 8 hours 27 minutes, and these now constitute $56 \%$ of the meetings.

The symposiums are intended to be international. The extent to which this objective had been achieved was assessed by examining the country of origin of the participants (that is, the country in which the scientist was working at the time of the symposium). Overall, scientists from 68 countries participated, and the mean number of countries represented at each recent symposium was $7 \cdot 5$ (mean number of participants 25). Sequences of 20 symposiums were examined at four year intervals (table II). The level of participation by scientists from the United Kingdom decreased from $55 \%$ to $33 \%$ and that by scientists from North America increased from $22 \%$ to $40 \%$, while the proportions from other regions remained fairly constant.

Discussion periods are a major feature of these meetings, and the pattern of contributions to the discussion was examined in detail from the printed record of the 20 most recent symposiums (figure). The number of substantive contributions to discussion in these symposiums ranged from 460 to 862 (mean 654, SD 106), the mean time required for each contribution ranging from 33 to 71 seconds. The most active contributors made almost

TABLE II-Proportions (\%) of scientists from different regions attending symposiums. (Symposiums selected in groups of 20 during 1951-84)

\begin{tabular}{|c|c|c|c|c|}
\hline \multirow[b]{2}{*}{ Dates } & \multicolumn{4}{|c|}{ Region } \\
\hline & United Kingdom & North America & Western Europe* & Others \\
\hline $1951-5$ & $55 \cdot 2$ & $22 \cdot 3$ & $20 \cdot 9$ & $1 \cdot 6$ \\
\hline $1960-4$ & $48 \cdot 3$ & $27 \cdot 5$ & $17 \cdot 9$ & $6 \cdot 3$ \\
\hline $1968-71$ & $43 \cdot 9$ & $26 \cdot 4$ & $20 \cdot 8$ & 8.9 \\
\hline $1974-6$ & $52 \cdot 3$ & $24 \cdot 6$ & $16 \cdot 7$ & $6 \cdot 4$ \\
\hline $1980-3$ & $41 \cdot 8$ & $32 \cdot 9$ & $17 \cdot 3$ & $8 \cdot 0$ \\
\hline $1983-4 \dagger$ & $32 \cdot 7$ & $40 \cdot 4$ & $20 \cdot 3$ & $6 \cdot 5$ \\
\hline
\end{tabular}

^ Excludes United Kingdom.

+ Group of 10 records up to last symposium.
$12 \%$ of the total contributions (range $8 \cdot 3-19 \cdot 0 \% ; 50-135$ contributions) while the median contributors made $3 \cdot 0-4 \cdot 3 \%$ of the total (16-33 contributions). Altogether $99 \%$ of all participants contributed actively, and this analysis showed that $93 \%$ made five or more contributions and $85 \% 10$ or more.

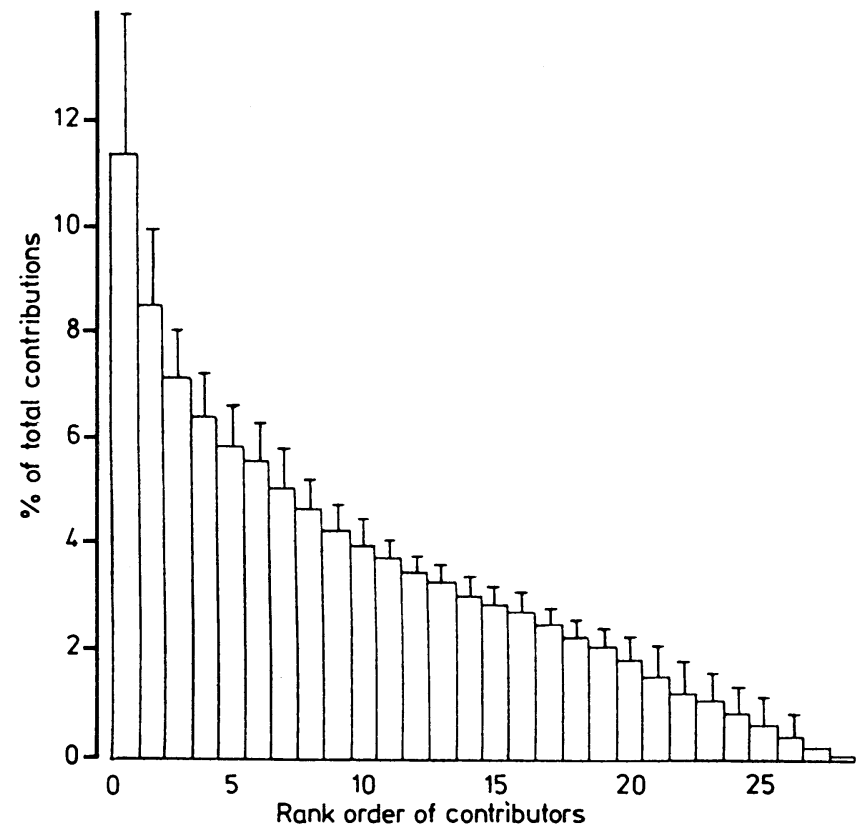

Proportion of contributions by individual participants. Mean (SD) values from 20 consecutive symposiums.

These data were further analysed to assess the contributions of those who presented formal papers and those who did not. Those who presented papers, as expected, made more contributions to the discussion, but many of these were made in the discussion period immediately after their own paper. Direct comparison between the two groups was made by noting the number of contributions made by those who gave papers, excluding those made immediately after their own papers, and the number made by participants who did not give papers, reduced by the factor $(n-1) / n$ (where $n$ was the number of discussion periods). The mean number of contributions by those who presented papers was $17 \cdot 1$ and by those who did not present papers $15 \cdot 8$ on this basis, and this difference was not significant.

An analysis of the proportions of contributions by participants from different geographic regions was made to try to establish whether scientists engaged in research at the highest level in non-anglophone countries are at a disadvantage compared with those from North America, the United Kingdom, and Australasia. There were no significant differences in the level of participation between those from different geographic regions who did not present papers. There were some differences, however, between those from the different regions who did present a paper, the Australasians being the most vocal; these differences reached significance in some cases (table III). The scientists from North America who gave papers made significantly more contributions than those from Western Europe (excluding the United Kingdom) while the scientists from the United Kingdom occupied an intermediate position. The numbers of participants from Eastern Europe, Asia, Africa, and Central and South America were too small to permit statistical comparison but the numbers of contributions from these groups were similar to those from Western Europe.

TABLE III-Number of contributions by scientists from different geographical regions who presented papers at 20 consecutive symposiums, and significance compared with other regions. Analysis by Scheffé's multiple comparison method ${ }^{13}$

\begin{tabular}{|c|c|c|c|c|c|}
\hline & \multirow[b]{2}{*}{$\begin{array}{l}\text { Mean (SD) No } \\
\text { of contributions }\end{array}$} & \multicolumn{4}{|c|}{ Significance } \\
\hline & & Australasia & $\begin{array}{l}\text { North } \\
\text { America }\end{array}$ & $\begin{array}{c}\text { United } \\
\text { Kingdom }\end{array}$ & $\begin{array}{l}\text { Western } \\
\text { Europe }\end{array}$ \\
\hline $\begin{array}{l}\text { Australasia } \\
\text { North America } \\
\text { United Kingdom } \\
\text { Western Europe }\end{array}$ & $\begin{array}{l}44 \cdot 6(16 \cdot 8) \\
32 \cdot 8(16 \cdot 9) \\
28 \cdot 9(15 \cdot 4) \\
25 \cdot 6(12 \cdot 6)\end{array}$ & $\begin{array}{c}\text { NS } \\
\mathrm{p}<0.01 \\
\mathrm{p}<0.01\end{array}$ & $\begin{array}{c}\text { NS } \\
\text { NS } \\
p<0.05\end{array}$ & $\mathrm{p}<0.01$ & $\begin{array}{c}\mathrm{p}<0.01 \\
\mathrm{p}<0.05 \\
\text { NS }\end{array}$ \\
\hline
\end{tabular}




\section{IMPACT OF THE SYMPOSIUMS ON PARTICIPANTS}

Tables IV and V summarise the results obtained by sending questionnaires to all participants in 40 consecutive symposiums. Overall, $65 \%$ of participants rated the symposiums as excellent, $32 \%$ as good, and $3 \%$ as fair. None of the respondents graded the meetings as poor, although this option was offered on the questionnaire.

TABLE IV-Impact of symposiums on participants $(\mathrm{No}(\%))^{\star}$

\begin{tabular}{lrr}
\hline & \multicolumn{1}{c}{ Yes } & \multicolumn{1}{c}{ No } \\
\hline $\begin{array}{l}\text { Provided new information or ideas, or both } \\
\text { Altered direction or accelerated progress of participants }\end{array}$ & $732(98 \cdot 7)$ & $10(1 \cdot 3)$ \\
$\quad$ research & $364(50 \cdot 3)$ & $359(49 \cdot 7)$ \\
Established valuable new scientific contacts & $647(88 \cdot 4)$ & $85(11 \cdot 6)$ \\
Led to exchange of material with other participants & $437(60 \cdot 0)$ & $291(40 \cdot 0)$ \\
Provided basis for collaborative research projects & $226(31 \cdot 3)$ & $497(68 \cdot 7)$ \\
Provided opportunities to visit other laboratories & $252(59 \cdot 0)$ & $175(41 \cdot 0)$ \\
$\quad$ (non-United Kingdom participants only) & &
\end{tabular}

* Total of 746 returns, though some returns did not include answers to every question.

TABLE V-Value of published proceedings to participants $(N o(\%))^{\star}$

\begin{tabular}{lccrr}
\hline & Excellent & Good & \multicolumn{1}{c}{ Fair } & \multicolumn{1}{c}{ Poor } \\
\hline For research purposes & $375(51 \cdot 6)$ & $283(38 \cdot 9)$ & $63(8 \cdot 7)$ & $6(0 \cdot 8)$ \\
For teaching purposes & $206(28 \cdot 1)$ & $337(46 \cdot 0)$ & $148(20 \cdot 2)$ & $41(5 \cdot 7)$ \\
Overall view of series & $385(54 \cdot 8)$ & $302(43 \cdot 0)$ & $16(2 \cdot 2)$ & $0(0 \cdot 0)$ \\
\hline
\end{tabular}

^ Total of 746 returns, though some did not include answers to every question.

\section{IMPACT OF THE SYMPOSIUMS ON THE SCIENTIFIC COMMUNITY AS A WHOLE}

The symposium proceedings are research publications, and their use by the research community was assessed by citation analysis using the Science Citation Index. The index for 1982 was used and a search carried out covering all symposiums published during 1972-82. Table VI summarises the results and shows the number of citations and impact factor (total number of citations divided by number of papers) in relation to year of publication. Impact factors for individual books ranged from $0 \cdot 14$ to $7 \cdot 39$. There was a latent period of five years between publication and peak rate of citation.

TABLE VI-Impact of Ciba Foundation's publications on the natural sciences

\begin{tabular}{cccc}
\hline $\begin{array}{c}\text { Year of } \\
\text { publication }\end{array}$ & $\begin{array}{c}\text { No of } \\
\text { papers }\end{array}$ & $\begin{array}{c}\text { No of } \\
\text { citations }\end{array}$ & $\begin{array}{c}\text { Impact } \\
\text { factor }\end{array}$ \\
\hline 1982 & 114 & 68 & $0 \cdot 596$ \\
1981 & 94 & 126 & $1 \cdot 340$ \\
1980 & 145 & 299 & $2 \cdot 062$ \\
1979 & 160 & 347 & $2 \cdot 169$ \\
1978 & 108 & 241 & $2 \cdot 231$ \\
1977 & 110 & 277 & $2 \cdot 518$ \\
1976 & 108 & 205 & $1 \cdot 898$ \\
1975 & 94 & 218 & $2 \cdot 319$ \\
1974 & 93 & 166 & $1 \cdot 785$ \\
1973 & 137 & 266 & $1 \cdot 942$ \\
1972 & 101 & 98 & 0.970 \\
\hline
\end{tabular}

^ Impact factor $=$ No of citations $/$ No of papers.

\section{Discussion}

The case for evaluating the outcome and process of scientific research has been argued by several authors. ${ }^{3.6}$ Several studies have been carried out using the techniques of direct and indirect performance evaluation to assess the scientific, social, and economic benefits of innovations, principally in the biosciences, medicine, physics, and radioastronomy. ${ }^{36-11}$ Little work has been done to evaluate the research process itself, and we are unaware of any published studies assessing the value of scientific meetings. The observations reported here can, therefore, be judged for only a limited range of criteria.

The symposiums are designed to be international and multidisciplinary and to encourage active participation by all those present. It is evident from these data, which show an active rate of participation of $99 \%$, that the last objective has been achieved. Performance has improved over the years, and allocating adequate time for discussion is probably an important factor. Other factors might possibly contribute, including "better" selection of participantsthat is, those who have important ideas or information to contribute-or the selection of an "in group" who are already familiar with each other's work. It is, of course, impossible to judge objectively whether selection processes have been improved, but it seems unlikely that this level of participation merely reflects exchanges between scientists already familiar with each other and their work as $98 \%$ indicated that they had acquired new information or ideas, or both, and $88 \%$ established valuable new scientific contacts. It is also impossible to show conclusively that the symposiums are multidisciplinary as the limits of a discipline cannot be clearly defined. Nevertheless, an average of nine major disciplines as defined by the title of the relevant department or institute-for example, physiology, biochemistry, genetics, organic chemistry, etc-were represented at each symposium. The symposiums were clearly international, and to a certain extent the geographical areas from which the participants were drawn reflect the world distribution of scientific research. Comparison of these data with those published by Garfield on rates of citation indicate that the United Kingdom is relatively over-represented and the North American continent under-represented, while the proportion of those who attend from other regions closely reflects their scientific output and impact. ${ }^{12}$ The disproportion between the United Kingdom and the United States has been noted, and table II indicates that symposiums in recent years have more clearly reflected the geographic distribution of good quality scientific research.

The pattern of contributions to discussion was examined from the printed record. The symposiums clearly provide an environment in which vigorous discussion may take place with the effective participation of almost all members of the group. Our use of the printed record for the analysis is, however, open to criticism, although it is the foundation's policy that the published version should mirror the verbal exchanges as closely as possible. The editorial process removes from the transcript such items as the chairman calling participants' names, pleas for clarification and repetition, and also laughter, non-constructive interruptions, and abuse. Contributions may also be abbreviated as some scientists clearly operate with a lower "signal to noise" ratio than others. Our observations, therefore, relate to substantive contributions to the discussion - that is, clear cut questions, statements, comments, and speculations. It might be argued that the unedited transcript would have been more satisfactory source material for these observations, but this also has its disadvantages as judgments have to be made on trivial remarks - for example, requests for clarification, or a suggestion that another participant might comment-interruptions, and occasions on which two or more participants speak simultaneously. Thus the analysis was restricted to substantive contributions, the judgments having been made by an independent professional editor.

It is widely accepted that English is now the international language of science and particularly of high level scientific research. It does not necessarily follow, however, that those whose mother tongue is not English are able to participate in discussion on equal terms. Participants were classified by the region in which they were working at the time of the symposium, although clearly some whose native language was not English were working in anglophone countries and vice versa. The available data suggested that participants from non-anglophone countries in Europe and elsewhere were at a disadvantage, although this was relatively minor. Participants from the United Kingdom occupied (appropriately perhaps) a position between those from North America and other Western European countries.

The symposiums clearly provide an opportunity for scientists from many countries to meet and discuss their work. The question then arises whether they have a positive influence on the progress of research. We assessed their impact on the participants by questionnaire and on the scientific community in general by citation (1) 
analysis. The response to a single mailing of a questionnaire to participants (over 80\%) was good: almost all participants expressed the view that participation had been valuable, had provided new information or ideas, or both, and had provided an opportunity to establish valuable new scientific contacts. The response to those questions requiring more objective replies was also encouraging. The subsequent exchange of research material among participants $(60 \%)$ and the development of collaborative projects (over $30 \%$ of participants) were positive outcomes of the symposiums.

The impact of the symposiums on the scientific community was assessed by citation analysis as this technique provides a direct measure of usefulness to the research community. Analysis of sales provides limited information as most books are purchased by libraries and the numbers sold fluctuate relatively little. Our observations can also be compared with the figures published by the Institute for Scientific Information, which has a package that ranks journals and covers roughly 4500 publications. Each year of publication the Science Citation Index calculates a mean impact factor for the preceding two years-for example, for 1980 and 1981 in the 1982 index. Comparison of the impact factor for Ciba Foundation publications on the same basis would place these volumes in the top $15 \%$-that is, at the same level as many of the better quality specialist journals. The peak time for an article to be cited in journals, however, occurs two years after publication, whereas for the foundation's publications this figure is five years and the period of frequent citation is much longer than for journals. Direct comparison of peak rates of citation improves the ranking of the foundation's publications by more than 200 places and puts them well within the top $10 \%$ of all scientific publications. This high position has been achieved despite several factors that would tend to limit the number of citations, including the fact that not all papers contain new data, techniques are rarely described in detail (these publications commonly attract the highest citation rates), and the policy of some journals excludes references to symposium volumes. The other observation worthy of comment is the impact factor of 0.596 in the year of publication (the immediacy index), which would place the foundation's volumes 276th out of more than 4000 publications. This is a strikingly high figure considering that journals are distributed on publication to subscribers whereas books have to be promoted and sold and thus take rather longer to reach their readers. These observations indicate that symposium volumes are cited early, often, and over a substantial period.

These data clearly show that small, carefully organised multidisciplinary meetings can make a positive contribution to scientific research and that they are of value to the participants and the scientific community at large. Performance evaluation of the processes of science is difficult and controversial. Nevertheless, both the outcome and the processes of research, including evaluation of scientific meetings, can be assessed systematically, as we have shown. It is essential that the scientific community should be prepared to take on the responsibility of measuring research performance to justify the continuing commitment of public and private funds to research.

\section{References}

1 Dobbing J. Less listening, more discussion. Br Med f 1981;283:503.

2 Freedman R. Specialist jamboree- - who benefits? New Scientist 1977:76:98-9.

3 Comroe JH, Dripps RD. Scientific basis for the support of biomedical sciences. Science 1976;192:105-11.

4 Gibson JE. Performance evaluation of academic research. Science 1979;206:407.

5 Mosteller F. Innovation and evaluation. Science 1981;211:881-6.

6 Fudenberg $\mathrm{HH}$. Basic biomedical research. A cost benefit analysis. In: Fudenberg $\mathrm{HH}$ ed Biomedical institutions, biomedical funding and public policy. New York: Plenum Publishing, Biomedical instir

1983: 11-39

7 Margolis J. Citation indexing and evaluation of scientific papers. Science 1967;155:1213-9.

8 Garfield E. Citation analysis as a tool in journal evaluation. Science 1972;178:471-9.

9 Cole JR, Cole S. The Ortega hypothesis. Science 1972;178:368-75.

10 Martin BR, Irvine J. Assessing basic research: some partial indicators of scientific progress in radioastronomy. Research Policy 1983;12:61-90.

11 Irvine J, Martin BR. Assessing basic research-the case of the Isaac Newton telescope. Social Studies of Science 1983;13:49-86.

12 Garfield E. Mapping science in the Third World. Science and Public Policy 1983;10:112-27. 13 Scheffé $\mathrm{H}$. Analvsis of variance. London: Wiley, 1959.

(Accepted 21 fune 1985)

\section{Dernford Hospital, Plymouth PL6 8DH}

SHEENA REILLY, MB, MRCPATH, consultant microbiologist, Plymouth Public Health Laboratory

DOROTHY CULLEN, MFCM, DPH, district officer

M G DAVIES, MB, MRCP, consultant dermatologist

Correspondence to: Dr Sheena Reilly.
On 27 August 1984 an 81 year old single woman was admitted to the hospital after a fall at home. In the preceding four months she had been treated by her general practitioner with several courses of topical steroids for a pruritic maculopapular rash. At the time of admission the rash was confluent and intensely itchy in spite of regular doses of oral antihistamines. She had been treated for scabies in 1983.

On examination the consultant dermatologist diagnosed late onset psoriasis for which she received emulsifying ointment and parenteral methotrexate. Her symptoms persisted and she became confused and agitated. On 16 September detailed dermatological examination revealed scabies burrows on her hands, and the diagnosis was amended to crusted scabies. She was given three daily courses of gamma benzene hexachloride, which was applied to the whole body, including the scalp, because of the widespread skin lesions. The extensive rash was slow to resolve, and she was given a fourth course of gamma benzene hexachloride on 26 September. 